\title{
Triaging children - keep it simple, swift and safe
}

Triage - or sorting - is a keystone of good emergency practice Emergencies must be prioritised according to need to avoid unacceptable delays, and for some patients poorer outcomes. Sadly, triage is not practised in many hospitals and health centres in Africa. Nolan et al. undertook a survey of mainly district-level hospitals in seven low-income countries in 2001 and found that triage, and with it much of emergency care, was badly done. ${ }^{[1]}$

Why? Is it because medicine has been taught to generations of doctors at the bedside with the patient tucked up in bed, and with little consideration of how he/she got there or of the difficulties and steps along the route to admission? While this is a good way to learn differential diagnoses, it is no way to learn about healthcare systems or to question who is (and who is not) admitted to hospital, and how and why

Is it because inpatient care has been 'divorced' from outpatient and emergency care in many large hospitals? In most smaller health units the outpatient and emergency departments are combined and share the same space and staff. ${ }^{[2]}$ Inpatient specialists may attend emergencies during their 'on calls', but feel no responsibility for the overall management and running of that department. The sorting, prioritising and immediate care of the children attending the hospital are typically left to the least experienced and least trained of all the healthcare staff. It is they who decide who is to be admitted or sent home, often without recourse to senior opinion because there is no senior member of staff to offer supervision to them or to the unit.

The World Health Organization prepared a guideline for managing children in the community called the Integrated Management of Childhood Illnesses and a guideline for inpatient care of children with severe illnesses and malnutrition. However, to provide seamless care, attention needs to be paid to the interface between the two. ${ }^{[3,4]}$
To fill this gap, a training programme was developed called ETAT - Emergency Triage, Assesssment and Treatment - in which identifying emergencies or priorities is emphasised and initial emergency treatments are outlined. ${ }^{[5]}$ Like all forms of training in life support, ETAT is organised according to ABC (airway, breathing and circulation). It is designed for use where few staff with a minimum of equipment are dealing with large numbers of patients. The triage part was validated against the 'gold standard' of Advanced Paediatric Life Support and found to be effective. ${ }^{[6]}$

ETAT has been introduced successfully in many hospitals. In the large national hospital in Blantyre, Malawi, the inpatient mortality rate of $11-18 \%$ fell to $8-11 \%$ after ETAT was introduced. ${ }^{[7]}$ It now stands at $4 \%$. In the recent FEAST multi-country trial of fluid therapy for severely ill children, an anticipated mortality of up to $20 \%$ was reduced to $10 \%$, probably because teaching of ETAT formed part of the pre-trial training. ${ }^{[8]}$

ETAT is a framework on which to build or individualise care. It is not meant to restrict what a clinician can do, but rather to provide a simple, rapid and effective management scheme for use where personnel, expertise and support are limited. Several adaptations have been made. In Kenya, management of common illnesses and newborn care have been added to the basic ETAT course to form ETAT $+{ }^{\left[{ }^{[9]}\right.}$ In Malawi, a day of trauma and burns care has been added. In Botswana and South Africa, where laboratory and radiological support are more consistently available, some modifications have been made to the treatment plans (personal communications, Jonathan Silverman and Baljit Cheema, 2011).

At Red Cross War Memorial Children's Hospital (RCCH), Cape Town, as reported in this issue of SAMJ, weight, temperature and oxygen saturation measurements (in children with obvious 


\section{EDITORIAL}

respiratory distress) have been added to triage. ${ }^{[10]}$ We are not told what cut-offs were used to assign a child to a particular triage category, but if volume of workload and staffing allow, these seem sensible additions.

The RCCH emergency team compared ETAT triage results with those from the South African Triage Scoring (SATS) system, which includes physiological parameters to develop a triage early warning score (TREWS). ${ }^{[11]}$ As the authors point out, these are important criteria but are not needed at the point of entry to hospital to be able to assign a triage category. They are time consuming to perform and, if manually and hastily undertaken, could be incorrect. Also in paediatrics a normal blood pressure may give a false sense of security, as blood pressure often falls late and precipitously in children with shock.

Triage should be undertaken at all levels of health facilities, and ETAT is simple enough to be useful in health centres and in the community. Moreover, it can be taught to non-clinical staff.

Any tool that improves the care of and ultimately the outcome for the children we treat is valuable. One that can be introduced at almost no extra cost and with no additional staff is an added bonus. As with many circumstances in the life of health workers at every level, it is doing simple things well that forms the basis of good clinical service.

\section{E M Molyneux}

Paediatric Department, College of Medicine, Box 360, Blantyre, Malawi emmolyneux@gmail.com

1. Nolan T, Angos P, Cunha AJ, et al. Quality of hospital care for seriously ill children in less developed countries. Lancet 2001;357(9250):106-110.

Molyneux E. Paediatric emergency care in resource-constrained health services is usually neglected: It is time for change. Ann Trop Paediatr 2010;30(3):165-176.

3. World Health Organization. Improving Child Health: Integrated Management of Childhood Illness. Geneva: WHO, 1999

World Health Organization. Management of the Child with a Serious Infection or Severe Malnutrition Guidelines for Care at the First Referral Level in Developing Countries. Geneva: WHO, 2000.

5. Emergency Triage Assessment and Treatment Course. http://www.who.int/child_adolescent_health/ documents/9241546875/en/index.html (accessed 1 November 2012).

6. Tamburlini G, Di Mario S, Maggi RS, Vilarini JN, Gove S. Evaluation of guidelines for emergency triage assessment and treatment in developing countries. Arch Dis Child 1999;81(6):478-482. [http://dx.doi. org/10.1136/adc.81.6.478

7. Molyneux EM, Ahmad S, Robertson A. Improved triage and emergency care for children reduces inpatient mortality in a resource-constrained setting. World Health Bulletin 2006;84(4):1-6. [http://dx.doi. org/10.2471/BLT.04.019505]

8. Maitland K, Kiguli S, Opoka RO, et al.; FEAST Trial Group. Mortality after fluid bolus in African children with severe infection. N Engl J Med 2011;364(26):2483-2495. [http://dx.doi.org/10.1016/S0140-6736(12)60260-8] 9. Irimu G, Wamae A, Wasunna A, et al. Developing and introducing evidence based clinical practice guidelines for serious illness in Kenya. Arch Dis Child 2008;93(9):799-804. [http://dx.doi.org/10.1136/ adc.2007.126508]

10. Buys H, Westwood C, Richardson D, Westwood A, Muloiwa R. An adapted triage tool (ETAT) at Red Cross War Memorial Children's Hospital Medical Emergency Unit, Cape Town, South Africa: An evaluation. S Afr Med J 2013;103(3):161-165 (this issue). [http://dx.doi.org/10.7196/SAMJ.6020]

11. Bruijns S, Wallis L, Burch V. A prospective evaluation of the Cape Triage Score in the emergency department of an urban public hospital in South Africa. Emerg Med J 2008;25:398-402. [http://dx.doi.org/10.1136/ emj.2007.04911.

S Afr Med J 2013;103(3):158-159. DOI:10.7196/SAMJ.6531 